\title{
Experimental Research on Relationship between UHF Partial Discharge Signals and Discharge Quantity in GIS
} \author{
Xiaoxing Zhang ${ }^{2}$, Jian Zhang ${ }^{2}$ \\ ${ }^{1}$ Electric Power Science Research Institute, Guizhou Power Grid Co., Ltd, Guiyang 550000, China \\ ${ }^{2}$ School of Electrical Engineering, Wuhan University, Wuhan 430000, China \\ ${ }^{3}$ Guiyang Power Supply Burea, Guizhou Power Grid Co., Ltd, Guiyang 550000, China \\ ${ }^{4}$ Liupanshui Power Supply Burea, Guizhou Power Grid Co., Ltd, Liupanshui 553000, China \\ ${ }_{5}^{5}$ Duyun Power Supply Burea, Guizhou Power Grid Co., Ltd, Duyun 558000, China \\ ${ }^{6}$ Tongren Power Supply Burea, Guizhou Power Grid Co., Ltd, Tongren 554300, China
}

Tao Yang ${ }^{1}$, Jianrong $\mathrm{Wu}^{1}$, Guozhi Zhang ${ }^{2}$, Liang Huang ${ }^{2}$, Qiansu $\mathrm{Lv}^{2}$, Lin Zhang ${ }^{3}$, Li Huang ${ }^{4}$, Siyang $\mathrm{He}^{5}$, Shuai Wang ${ }^{6}$,

\begin{abstract}
Apparent discharge quantity is usually recognized as judgement standard for severity of partial discharge in the field of electrical equipment insulation diagnosis. In recent years, the ultra-high-frequency (UHF) method has been widely used due to its unique advantages on on-line monitoring and positioning, but the relationship between UHF partial discharge signals and discharge quantity is still a difficult problem of UHF method. In order to research relationship between UHF partial discharge signals and discharge quantity in GIS, a large number of experiments, based on four kinds of typical insulation defects in the GIS, are carried out. Degree of correlation, between parameters including UHF energy, quadratic integral, peak voltage, peak-to-peak value, wave area and discharge quantity, the square of discharge quantity, is studied based on coefficient of determination. The experimental results show there is linear relation between UHF signal energy and the square of discharge quantity with high related degree.
\end{abstract}

\section{Introduction}

GIS, employing SF6 as insulation media, has received extensive application in electric network transformation and construction due to its many advantages such as small land occupancy, stable and reliable operation, suffering little by outer environment as well as less maintenance work[1]. Operating experiences indicate that the inner inevitable defects of GIS would still cause troubles and gradually deteriorate the devices although their high reliability, leading to the occurrences of major accidents. As a main factor of the induction of these accidents, the Partial discharge (PD) has aroused considerable researches by scholars and institutions. Currently, the relatively successful detection method for PD is pulse current method and ultra-high frequency (UHF) method [2-7].

The pulse current method is the only quantitative detection method that meets the international criterion [8]. Although it has some advantages of high sensitivity and quantitative detection for discharge capacity, its limitations of low detecting frequency and susceptibility to electromagnetic interference result in its inapplicability for on-site test. In terms of UHF method, it utilizes the antenna sensors installed inside or outside of GIS to receive UHF signals motivated by PD with frequency ranging from 300 to $3000 \mathrm{MHz}$ and to proceed further detection and analyses. Such means possess the merits of high ant jamming capability, adoptability for fault localization and fault type recognition. However, this technology at present fails to detect the discharge capacity of inner defects quantitatively.

In recent years, a small number of researches have theoretically analyzed and experimentally investigated the dependence between UHF signals and discharge capacity, with related experiments limited in the focus of needle plate (metal protrusions) defects [10-11]. This paper performed a large number of experiments about four kinds of typical defects including GIS metal protrusions, free metal particles, surface pollutants of the insulators and air gap between high voltage conductor and insulators, putting forward the relationship between the discharge capacity and UHF signals. This progress would provide important reference value and guiding role for UHF method to realize the quantitative detection of partial discharge in power equipment.

\section{Experiment system and experimental method}

\subsection{Experimental equipment}

In this experiment, pulse current method is adopted based on IEC 60270 standard; In UHF test, the measured 
signal is UHF electromagnetic signal, which is the amplitude of electromagnetic signal with $\mathrm{mV}$ as a unit. Experimental circuit is shown in figure 1

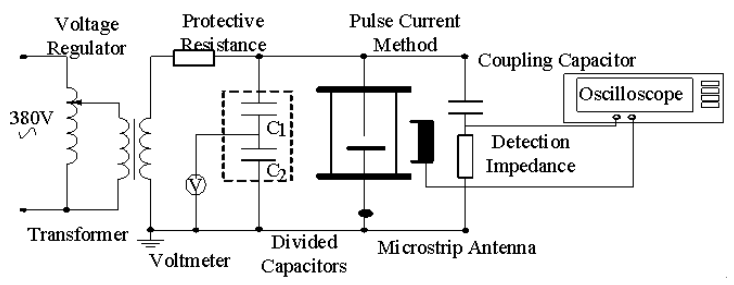

Fig 1. Experimental circuit

\subsection{Analysis method on experiment data}

In order to study the relationship between UHF signal and its apparent discharge, UHF signal is processed via a variety of mathematical methods, which are respectively expressed as UHF signal peak voltage Umax, peak-to-peak value Upp, wave area Sw, energy Es and quadratic integral $\mathrm{I}_{\mathrm{II}}$. Discharge quantity $\mathrm{Q}$ and discharge quantity square $\mathrm{Q}^{2}$ of the pulse current signal are simultaneously calculated. The UHF signal energy Es can be calculated by:

$$
E_{\mathrm{s}}=\frac{\Delta t}{R} \sum U_{i}^{2}
$$

Where, $U_{i}$ is the voltage amplitude of NO.i sampling point of UHF signals. $\mathrm{R}$ is the load impedance, and $\mathrm{R}$ is $50 \Omega$. $\Delta t$ is the time difference between adjacent sampling points, and $\Delta t$ is $0.1 \mathrm{~ns}$.

Regression analysis are applied on all the experimental data analyzed regression. The concept of coefficient of determination $f_{\mathrm{d}}$ is introduced to describe the degree of regression. The so-called coefficient of determination is a parameter which is used to determine the degree of closeness of the sample observations around the sample regression line. Ranging between 0 and 1 , the larger the value of the coefficient of determination is, the higher the degree of correlation among variables, and conversely, the lower the correlation between variables. The formula is following

$$
f_{d}=\frac{\mathrm{S}_{\mathrm{R}}}{\mathrm{S}_{\mathrm{T}}}=\frac{\sum_{i=1}^{n} W_{i}\left(\hat{y}_{i}-\bar{Y}\right)^{2}}{\sum_{i=1}^{n} W_{i}\left(Y_{i}-\bar{Y}\right)^{2}}
$$

Where, $Y_{i}$ is the NO.i observation value. $W_{i}$ is the weight corresponding to NO.i observations value, generally is set to $1 . \bar{Y}$ is the average value of observed values. $\hat{y}_{i}$ is the fitted value of NO.i observations value. $\mathrm{S}_{\mathrm{R}}$ is the regression sum of squares, reflecting the influence of the change of independent variables on the change of dependent variables. $\mathrm{S}_{\mathrm{T}}$ is total sum of square, or sum of squares of the difference between observed and fitted values, reflecting the total deviation of the $\mathrm{N}$ observations and their mean values of the dependent variable.

\section{Experimental result}

\subsection{Metal protrusion defect}

The partial discharge caused by the metal protrusion defect belongs to the typical corona discharge. In this paper, needle-plate electrode is used to simulate metal protrusion defect. The discharge is generated by adjusting the distance between needle and plate with the needle electrode connected to the high voltage side, and the plate electrode grounded.

Under the same metal protrusion defect, the partial discharge signals at different charge quantity are obtained by applying different voltages. The $f_{\mathrm{d}}$ value of each parameter of the UHF signals is shown in table I. Compared the $f_{\mathrm{d}}$ value of each parameter at different voltages in the table, it can be found that the UHF signals energy always has a high linearity with the square of charge quantity. Moreover, when the voltage is increased, the dispersion of metal protrusion defect discharge does not change, and the stability of the discharge remains unchanged.

Table 1. Setting Word's margins.

\begin{tabular}{|c|c|c|c|c|c|c|c|}
\hline \multirow{2}{*}{$\begin{array}{c}\text { voltage/ } \\
\mathrm{kV}\end{array}$} & \multirow{2}{*}{$\begin{array}{c}U_{\mathrm{ma}} \\
\mathrm{x}\end{array}$} & \multirow{2}{*}{$U_{\mathrm{pp}}$} & $S_{\mathrm{w}}$ & $\begin{array}{c}\text { line } \\
\text { ar }\end{array}$ & $\begin{array}{c}\text { quadra } \\
\text { tic }\end{array}$ & \multirow{2}{*}{$Q^{2}$} & \multirow{2}{*}{$I_{\mathrm{II}}$} \\
\hline 7 & 0.9 & 0.9 & 0.9 & 0.9 & 0.977 & 0.9 & 0.9 \\
& 47 & 22 & 76 & 76 & & 78 & 74 \\
\hline \multirow{2}{*}{9} & 0.9 & 0.9 & 0.9 & 0.9 & 0.979 & 0.9 & 0.9 \\
& 55 & 28 & 79 & 73 & & 77 & 79 \\
\hline \multirow{2}{*}{10} & 0.9 & 0.9 & 0.9 & 0.9 & 0.976 & 0.9 & 0.9 \\
& 49 & 21 & 75 & 58 & 0.9 & 75 \\
\hline
\end{tabular}

Taking the discharge at $9 \mathrm{kV}$ voltage as an example, the relationship between the UHF signal and the charge quantity is obtained, as shown in figure 2. It can be seen from the figure that the effect applying parabolic fitting is better than that of linear fitting about the relationship between the UHF signal energy and the charge quantity, and there is a linear relationship between the UHF signal energy and the square of charge quantity.

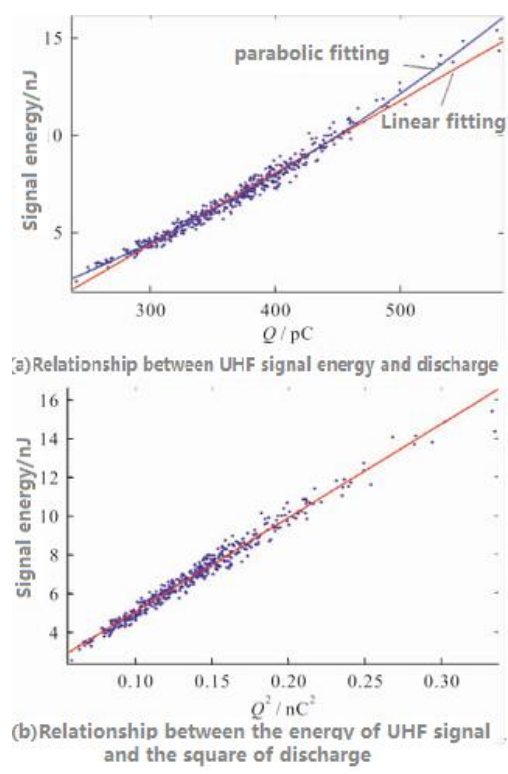

Fig 2. Relationship between UHF signal and charge quantity $9 \mathrm{kV}$ volatage 
It is shown in figure 3 that the relationship between the signal energy and the square of charge quantity under the same partial discharge source at $7.0,9.0$ and $10.0 \mathrm{kV}$. With the increase of the voltage, the UHF signal energy has an increasing tendency, but the experimental data can be regressed to the same line under different voltages. Therefore, this relationship can be used to quantify the charge quantity for metal protrusion defect.

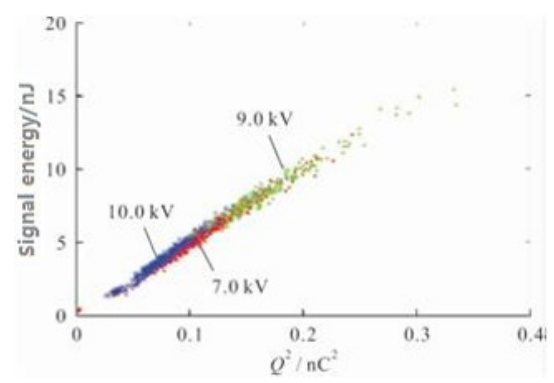

Fig 3. Relationship between UHF signal and charge quantity at different volatage

\subsection{Free metal particles defect}

Under the action of the external electric field, the free metal particles can induce charges and will jump or shift, which will greatly reduce the breakdown voltage of the gas insulation. In this paper, a series of rectangular thin aluminum sheets, which sizes are $2 \mathrm{~mm} \times 2 \mathrm{~mm}$, are placed between the high and low voltage electrodes of the experimental device to simulate this discharge type.

Under the same free metal particles defect, the partial discharge signal at different charge quantity is obtained by applying different voltages. The $f_{\mathrm{d}}$ value of each parameter of the UHF signals is shown in table 2. It can be seen that with the increase of the voltage, the higher the coefficient of determination of the data, which shows that the discharge of free metal particles tends to be stable at higher voltage. But in general, the dispersion of the datum is large. Meanwhile, no matter which kind of voltages, it is the best that the linear relationship between the UHF signal energy and the square of charge quantity under the free metal particles defect. Taken the discharge caused by free metal particles at $4 \mathrm{kV}$ voltage as an example, the relationship between the UHF signal energy and the charge quantity is obtained, as shown in figure 4.

Figure 5 shows the relationship between the energy of the UHF signal and the square of discharge under 3.6, 4.0 and $6.0 \mathrm{kV}$.

As can be seen from the figure 5, although the low voltage data linearity is slightly lower, but the experimental data at different voltages can be roughly returned to the same straight line.

Table 2. $f_{\mathrm{d}}$ of UHF signals on Free metal particles defect.

\begin{tabular}{|c|c|c|c|c|c|c|c|}
\hline \multirow[b]{2}{*}{$\begin{array}{c}\text { voltage/ } \\
\mathrm{kV}\end{array}$} & \multirow[b]{2}{*}{$\underset{\mathbf{x}}{U_{\mathrm{ma}}}$} & \multirow[b]{2}{*}{$U_{p p}$} & \multirow[b]{2}{*}{$S_{\mathrm{w}}$} & \multicolumn{2}{|c|}{$\boldsymbol{E}_{\mathrm{s}}$} & \multirow[b]{2}{*}{$Q^{2}$} & \multirow[b]{2}{*}{$\boldsymbol{I}_{\mathrm{II}}$} \\
\hline & & & & $\begin{array}{c}\text { line } \\
\text { ar }\end{array}$ & $\begin{array}{c}\text { quadra } \\
\text { tic }\end{array}$ & & \\
\hline 3.6 & 0.7 & 0.7 & 0.4 & 0.76 & 0.794 & 0.7 & 0.5 \\
\hline & 73 & 47 & 39 & 7 & & 94 & 20 \\
\hline 4.0 & 0.8 & 0.6 & 0.6 & 0.84 & 0.849 & 0.8 & 0.6 \\
\hline
\end{tabular}

\begin{tabular}{|c|c|c|c|c|c|c|c|}
\hline & 24 & 72 & 09 & 2 & & 48 & 74 \\
\hline \multirow{2}{*}{6.0} & 0.7 & 0.6 & 0.9 & 0.91 & \multirow{2}{*}{0.920} & 0.9 & 0.9 \\
& 61 & 52 & 50 & 6 & & 19 & 14 \\
\hline
\end{tabular}
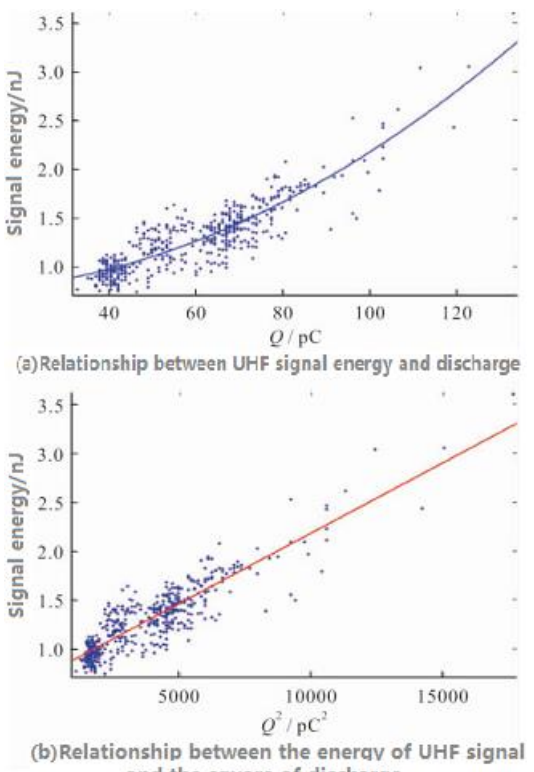
and the square of discharge

Fig 4. Relationship between UHF signal and charge quantity $4 \mathrm{kV}$ volatage

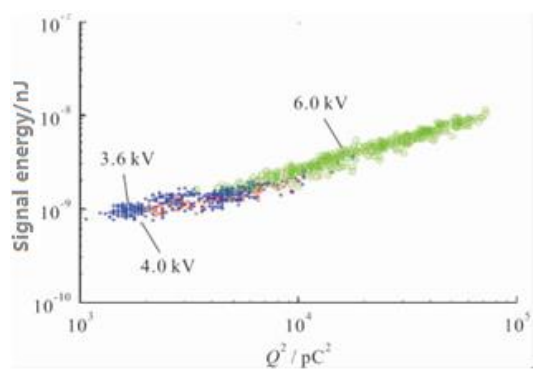

Fig 5. Relationship between UHF signal and charge quantity at different volatage

\subsection{Insulator surface contamination defect}

The discharge of metal contamination on insulator surface is between metal particle and insulator surface, therefore, the charge accumulation on insulator surface has an important influence on the discharge process. In this paper, the insulators with metal particles are placed between the high and low voltage electrodes to simulate the defects. The particle is aluminum sheet, the length is $10 \mathrm{~mm}$, the distance between the particles and the high voltage is $5 \mathrm{~mm}$.

By applying different voltages, the partial discharge signal under different discharge power is obtained, and the $f_{\mathrm{d}}$ value of each parameter of the UHF signal is shown in Table 3 Contrary to free metal particle defect, the linearity of the data is getting worse with the increase of voltage. The results show that the PD dispersion of metal contaminants on insulator surface increases at higher voltage, and the discharge is more and more unstable. However, it is still the best linear relationship between the UHF signal energy and the square of the discharge energy, the same as the first two defects. 
The relationship between UHF signal and discharge under $7 \mathrm{kV}$ voltage is shown in Figure 6. Figure 7 shows the relationship between the discharge energy and the square of the discharge power at the same local discharge power at $5.2,7$ and $9.0 \mathrm{kV}$. As can be seen from the diagram, the quantitative analysis of the linear relationship between the UHF signal energy and the square of the discharge will have a certain error in the case of high voltage.

Table 3. $f_{\mathrm{d}}$ of UHF signals on insulator surface contamination defect.

\begin{tabular}{|c|c|c|c|c|c|c|c|}
\hline \multirow[b]{2}{*}{$\begin{array}{c}\text { voltage/ } \\
\mathrm{kV}\end{array}$} & \multirow[b]{2}{*}{$\underset{\mathbf{x}}{\boldsymbol{U}_{\mathbf{m a}}}$} & \multirow[b]{2}{*}{$U_{\text {pp }}$} & \multirow[b]{2}{*}{$S_{\mathrm{w}}$} & \multicolumn{2}{|c|}{$E_{\mathrm{S}}$} & \multirow[b]{2}{*}{$Q^{2}$} & \multirow[b]{2}{*}{$\boldsymbol{I}_{\text {II }}$} \\
\hline & & & & $\begin{array}{c}\text { line } \\
\text { ar }\end{array}$ & $\begin{array}{c}\text { quadra } \\
\text { tic }\end{array}$ & & \\
\hline 5.2 & $\begin{array}{l}0.8 \\
17\end{array}$ & $\begin{array}{c}0.8 \\
66\end{array}$ & $\begin{array}{l}0.9 \\
71\end{array}$ & $\begin{array}{c}0.93 \\
6\end{array}$ & 0.971 & $\begin{array}{l}0.9 \\
70\end{array}$ & $\begin{array}{l}0.9 \\
61\end{array}$ \\
\hline 7.0 & $\begin{array}{l}0.6 \\
90\end{array}$ & $\begin{array}{l}0.6 \\
90\end{array}$ & $\begin{array}{l}0.8 \\
82\end{array}$ & $\begin{array}{c}0.87 \\
5\end{array}$ & 0.901 & $\begin{array}{l}0.8 \\
97\end{array}$ & $\begin{array}{l}0.8 \\
52\end{array}$ \\
\hline 9.0 & $\begin{array}{c}0.6 \\
51\end{array}$ & $\begin{array}{l}0.6 \\
89\end{array}$ & $\begin{array}{l}0.8 \\
42\end{array}$ & $\begin{array}{c}0.85 \\
4\end{array}$ & 0.868 & $\begin{array}{c}0.8 \\
68\end{array}$ & $\begin{array}{l}0.7 \\
99\end{array}$ \\
\hline
\end{tabular}
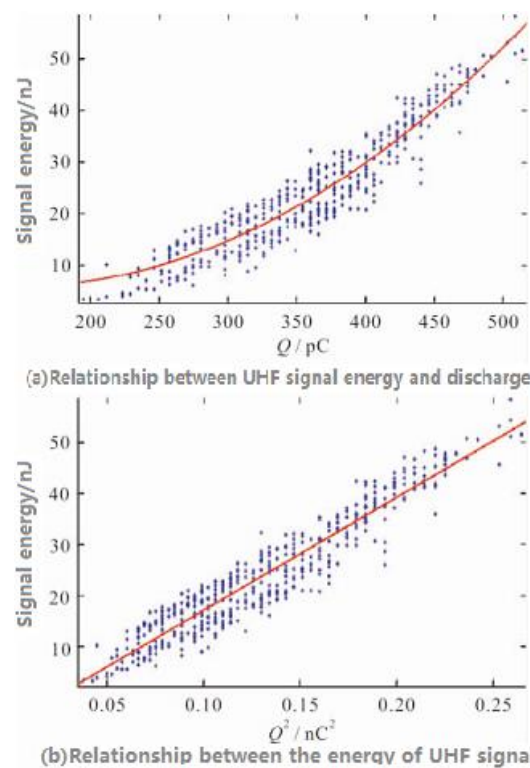
and the square of discharge

Fig 6. Relationship between UHF signal and charge quantity $7 \mathrm{kV}$ volatage

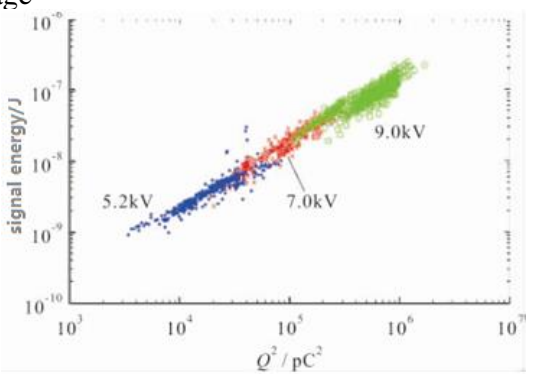

Fig 7. Relationship between UHF signal and charge quantity at different volatage

\subsection{Air gap defect between insulator and high voltage conductor}

There is an air gap between the medium and the electrode, which leads to internal partial discharge, which is related to the characteristics of the medium and the shape, size and position of the gap and the nature of the gas in the air gap. The insulator is placed between the high and low voltage electrodes, and the $3 \mathrm{~mm}$ gap between the insulator and the high voltage electrode is used to simulate the defects.

The $f_{\mathrm{d}}$ value of each parameter of the UHF signal is shown in Table 4. As can be seen from the table, the UHF signal energy and the square of discharge has always been a high degree of linearity. At the same time, when the voltage rises, the dispersion of the air gap defect between the insulator and the high voltage conductor decreases, and the discharge is more stable.

Table 4. $f_{d}$ of UHF signals on Electrode Gap defect.

\begin{tabular}{|c|c|c|c|c|c|c|c|}
\hline \multirow[b]{2}{*}{$\begin{array}{c}\text { voltage/ } \\
\mathrm{kV}\end{array}$} & \multirow[b]{2}{*}{$\underset{\mathbf{x}}{\boldsymbol{U}_{\mathbf{m a}}}$} & \multirow[b]{2}{*}{$U_{\mathbf{p p}}$} & \multirow[b]{2}{*}{$S_{\mathrm{w}}$} & \multicolumn{2}{|c|}{$E_{\mathrm{s}}$} & \multirow[b]{2}{*}{$Q^{2}$} & \multirow[b]{2}{*}{$\boldsymbol{I}_{\mathrm{II}}$} \\
\hline & & & & $\begin{array}{c}\text { line } \\
\text { ar }\end{array}$ & $\begin{array}{c}\text { quadra } \\
\text { tic }\end{array}$ & & \\
\hline 2.6 & $\begin{array}{c}0.8 \\
68\end{array}$ & $\begin{array}{l}0.9 \\
01\end{array}$ & $\begin{array}{c}0.8 \\
91\end{array}$ & $\begin{array}{c}0.8 \\
56\end{array}$ & 0.918 & $\begin{array}{c}0.9 \\
12\end{array}$ & $\begin{array}{l}0.8 \\
77\end{array}$ \\
\hline 6.0 & $\begin{array}{c}0.9 \\
11\end{array}$ & $\begin{array}{l}0.9 \\
31\end{array}$ & $\begin{array}{l}0.8 \\
25\end{array}$ & $\begin{array}{c}0.9 \\
15\end{array}$ & 0.945 & $\begin{array}{l}0.9 \\
47\end{array}$ & $\begin{array}{c}0.8 \\
18\end{array}$ \\
\hline 9.0 & $\begin{array}{c}0.9 \\
01\end{array}$ & $\begin{array}{l}0.9 \\
04\end{array}$ & $\begin{array}{l}0.9 \\
24\end{array}$ & $\begin{array}{l}0.9 \\
67\end{array}$ & 0.977 & $\begin{array}{l}0.9 \\
77\end{array}$ & $\begin{array}{l}0.9 \\
31 \\
\end{array}$ \\
\hline
\end{tabular}

The relationship between UHF signal and discharge under $9.0 \mathrm{kV}$ voltage is shown in Figure 8. Figure 9 shows the relationship between the discharge energy and the square of the discharge at the same local discharge power at 2.6, 6 and $9.0 \mathrm{kV}$. As can be seen from the figure, the experimental data at different voltages can be returned to the same straight line, so the UHF signal can be used to quantify the gap defects.
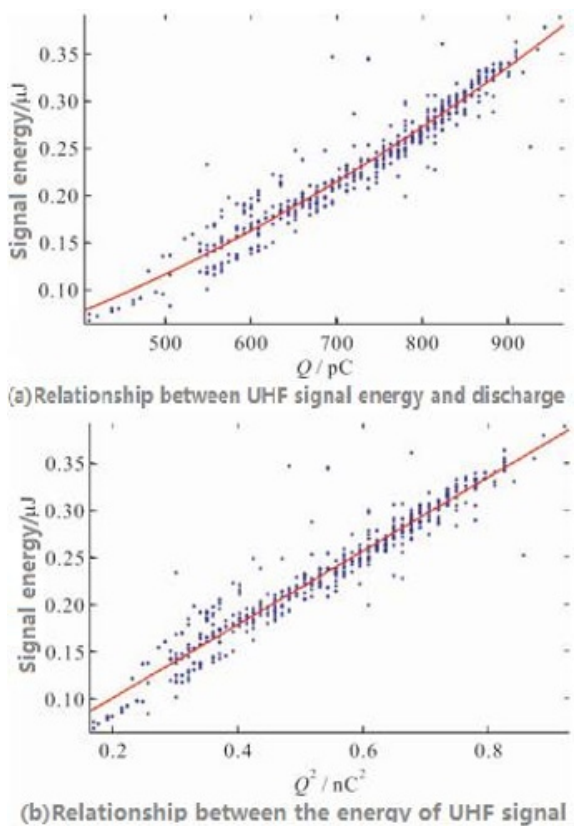

(b) Relationship between the enerqv of UHF signal and the square of discharge

Fig 8. Relationship between UHF signal and charge quantity $9 \mathrm{kV}$ volatage 


\section{Conclusion}

Based on a large number of experiments, the relationship between the UHF signal parameters and the discharge of 4 typical defects of GIS partial discharge is compared.

1) The linear relationship between the UHF signal energy and the square of the discharge of 4 kinds of defects in GIS has the highest coefficient of determination. That is to say, the linear relationship between the UHF energy and the square of the discharge (or the quadratic relationship between UHF energy and discharge) is the best regression curve.

2) UHF signal can be used to quantify the discharge of 4 kinds of typical defects, in which the error of metal defect is the lowest, which can reach $3 \%$. The free metal particles have the highest defects, which are basically more than $10 \%$. The error is: metal protrusion< air gap $<$ metal contamination on insulator surface $<$ free metal particle.

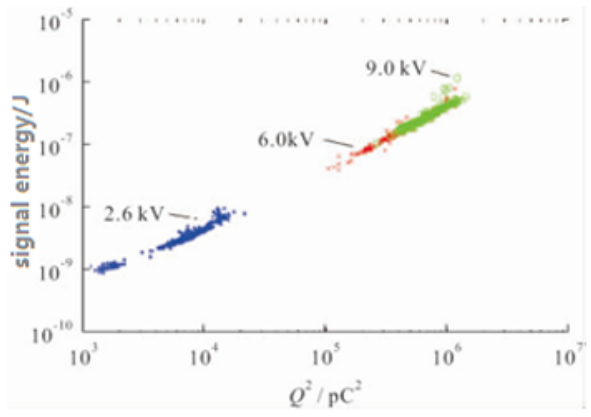

Fig 9. Relationship between UHF signal and charge quantity at different volatage.

\section{References}

1. K. D. Srivastava and M. M. Morcos, "A review of some critical aspects of insulation design of GIS/GIL systems," 2001 IEEE/PES Transmission and Distribution Conference and Exposition. Developing New Perspectives (Cat. No.01CH37294), Atlanta, GA, pp. 787-792 vol.2(2001)

2. M. D. Judd, O. Farish and B. F. Hampton, "The excitation of UHF signals by partial discharges in GIS," in IEEE T DIELECT EL IN vol. 3, no. 2, pp. 213-228 (1996)
3. J. S. Pearson et al., "Partial discharge diagnostics for gas insulated substations," in IEEE T DIELECT EL IN, vol. 2, no. 5, pp. 893-905, Oct (1995)

4. M. D. Judd, O. Farish and B. F. Hampton, "Broadband couplers for UHF detection of partial discharge in gas-insulated substations," in IEE Proceedings - Science, Measurement and Technology, vol. 142, no. 3, pp. 237-243 (1995)

5. M. D. Judd, B. F. Hampton and O. Farish, "Modelling partial discharge excitation of UHF signals in waveguide structures using Green's functions," in IEE Proceedings - Science, Measurement and Technology, vol. 143, no. 1, pp. 63-70(1996)

6. Zhou Qian, Tang Ju, Xu Zhongrong, Meng Yanhui and Zhang Xiaoxing, "Study on partial discharge of metallic outshoot insulation defect in GIS," Proceedings of 2005 International Symposium on Electrical Insulating Materials, (ISEIM 2005). pp. 431-434 Vol. 2 (2005).

7. Tang, Ju, et al. "Investigation of Partial Discharge on Typical Defects with UHF Detection Method for GIS." Przegląd Elektrotechniczny 88.12:351355(2012).

8. Standard, I. E. C. "High-voltage test techniques: partial discharge measurements." IEC-60270 (2000).

9. X. Zhang, S. Xiao, N. Shu, J. Tang and W. Li, "GIS partial discharge pattern recognition based on the chaos theory," in IEEE T DIELECT EL IN, vol. 21, no. 2, pp. 783-7 (2014)

10. G. P. Cleary and M. D. Judd, "UHF and current pulse measurements of partial discharge activity in mineral oil," in IEE Proceedings - Science, Measurement and Technology, vol. 153, no. 2, pp. 47-54, 9 March 2006.

11. S. Ohtsuka, T. Teshima, S. Matsumoto and M. Hikita, "Relationship between PD-induced electromagnetic wave measured with UHF method and charge quantity obtained by PD current waveform in model GIS," 2006 IEEE Conference on Electrical Insulation and Dielectric Phenomena, Kansas City, MO, , pp. 615-618(2006). 